\title{
The role of verbal humor in second language education
}

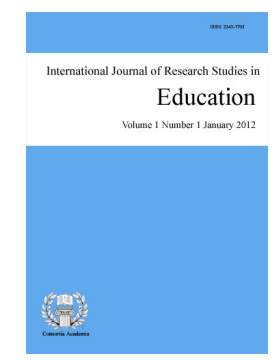

Ziyaeemehr, Ali $\bowtie$

Ministry of Education, Tehran, Iran (ziyaeeali@yahoo.com)

Kumar, Vijay

University of Otago, New Zealand (vijay.kumar@otago.ac.nz)

\section{Abstract}

Instructor humor serves a wide range of functions in educational contexts. This paper reports on a study that investigated the functions of instructors' humorous verbalizations in academic classrooms at a university where English is used as a second language. Data were collected through audio-recordings and classroom observations. The results of an inductive analysis led to the development of three major categories, namely "foregrounding form", "reinforcing meaning" and "highlighting cultural dissimilarities". These categories represented the strategies that served as instructional functions of humor in the context of L2 (second language) education. Findings indicate that using verbal humor in L2 classrooms offers opportunities to facilitate access to L2 linguistic and cultural knowledge resources that are embedded in humorous exchanges. Additionally, the findings suggest that L2 instructors must have specific (socio) linguistic and sociocultural humor competence to use humor to engage learners and communicate finer aspects of the L2. The implications of the findings are explored within the context of second language learning and teaching.

Keywords: verbal humor; humor functions; (socio) linguistic competence; second language acquisition; foregrounding form 


\section{The role of verbal humor in second language education}

\section{Introduction}

The role of effective communication in second language use has received increasing attention from second language acquisition (SLA) scholars in recent years. One of the most potent and strategic skills an instructor can draw on to facilitate L2 instruction and enhance the learners' communicative competence in a second language is the use of verbal humor. It is now widely recognized that to communicate effectively in a second language (L2), learners need to know much more than just the vocabulary and grammar of the target language. Besides linguistic knowledge, learners have to have acquired sociolinguistic and sociocultural input/skills to be able to comprehend and use a second language effectively in social interactions. This means that pressure is on academia to equip language instructors and educators with a repertoire of pedagogical skills that will enable them to help learners develop the required knowledge resources in the second language. Instructor humor is among the skills that can offer beneficial functions to L2 instructors in language classes. Examples of verbal or word-based humor include wordplays, funny stories, puns, content related jokes, comic irony, metaphor, teasing, hyperbole, metonymy, riddles, tongue twisters and, funny examples/stories

Humor is an interdisciplinary phenomenon and is often defined based on its immediate context of use. Generally, humor is understood as something that is appreciated, enjoyed, and shared by all people to be funny (Raskin, 1985; pp. 1-2) This study focuses on verbal or word-based humor, which refers to utterances the speaker intends to be amusing and where the presence of linguistic and contextual clues is necessary to support understanding (Norrick, 1993; Holmes, 2000).

\subsection{Functions of Humor}

Humor has only recently been of research interest to SLA scholars although the history of humor dates back to Plato and Aristotle (Morreall 1983; Raskin 1985). Researchers have looked into the role of humor from different perspectives that range from its function in informal social interactions to more formal situations such as educational settings. In general, social interaction humor functions as a strategy to express and reinforce solidarity with the audience (Hay, 2000), to reduce and relieve stress and tension (Martin, 2007; Schmitz, 2002), to buffer the effects of stressful tasks and to develop and maintain relationships (Fraley \& Aron, 2004; Priest \& Thein, 2003). Humor has also been characterized as a coping mechanism (Wanzer, et al., 2005), a tool for communicative support (Bippus, 2000), and a means of increasing patient compliance and satisfaction as well as physician credibility (Wrench \& Booth-Butterfield, 2003).

In educational settings, the use of humor is thought to increase instructional effectiveness (Wanzer, 2002), create a more enjoyable (Neuliep, 1991) and conducive learning environment (Davis, 2004; Wanzer et al., 2006), encourage student attention (Schmitz, 2002), increase student motivation (McCroskey et al., 2006), control frustration (Yoon et al., 2012) and clarify course material (Downs et al., 1988). Similarly, the value of humor in relation to course content has been consistently delineated in research (e.g., Garner, 2006; Gorham \& Christophel, 1990; Schmitz, 2002; Wanzer et al., 2009; Ziv, 1988). Studies suggest that effective humor is likely to enhance student acquisition/learning and retention of content. For instance, Ziv (1988) notes that the use of suitable, content-specific humorous examples may provide a student with a new perspective on the material being presented and this may lead to a novel cognitive insight. In light of this knowledge, language-related verbal humor warrants considerable attention especially in regard to its application in the ESL classroom.

Considering L2 contexts in particular, already there is a plethora of studies that support the significant role humor plays in understanding a second language (Bell, 2005) and facilitating L2 learning (Broner \& Tarone, 2001). Also, humor can be used to sensitize students to phonological, morphological, lexical, and syntactic 
The role of verbal humor in second language education

differences within a single language, or between a student's L1 and the target language (Deneire, 1995); it has even been suggested that learning to understand target language humor is essential for ESL/EFL acquisition/learning (Cook, 2002). Medgyes' (2002) work that explains how funny games, stories, jokes, puzzles, pictures, sketches, dialogues and so on can be fruitfully used in teaching at all levels of L2 learning provides additional insights into the role humor can play in L2 education.

It is evident from this body of research that there are strong social, psychological and instructional grounds for using humor in language instruction. However, the instructional function of verbal humor in ESL classrooms has received scant attention. A basic assumption is generally made that verbal humor offers opportunities to benefit second language learning and teaching. This derives from the view that communicating humor in a second language entails execution of various linguistic and cultural 'knowledge resources' (Raskin \& Attardo,1994) instilled in different layers of the language, which then become accessible to the learners through the use of verbal humor. That is, besides the primarily linguistic input transmitted through the textual devices/means (e.g., semantic, syntactic and phonological elements) in the language, verbal humor hosts various sociocultural and sociolinguistic nuances which L2 learners must acquire in order to communicate effectively with native speakers who share that knowledge. In light of this, it can be said that infusing verbal humor into L2 instruction (at different levels but particularly advanced levels) can benefit learners' L2 development and their overall "communicative competence" (Hymes, 1972).

The present paper examines the instructional functions of instructors' verbal humor in ESL classrooms but with a primary focus on aspects that can benefit L2 learning and teaching. More specifically, the paper addresses the question: What instructional functions can humor perform in the L2 learning environment? For the purpose of this study, "instructional functions" refer to those qualities of humor that serve to introduce, rehearse and illustrate the content/material of the target language and culture in instructional contexts.

\section{Methodology}

\subsection{Participants}

The participants in this study were university lecturers and students who were involved in ESL studies at a Malaysian university. Both undergraduate and postgraduate classes were included; the courses being taught were sociolinguistics, genre studies, teaching principles, English for Specific Purposes (ESP), research methodology and such like. Participants had different first language and cultural backgrounds that comprised local ethnic Malays, Chinese and Indians, and international students of Iranian, Indonesian, African, and Arab ethnicities. The lecturers were all Malaysians for whom English was their second language. All the observed lecturers had completed their postgraduate studies in English-speaking countries and were competent users of English due to their exposure to the linguistic and cultural subtleties of English in native contexts.

\subsection{Procedure}

The data sources for this research comprised classroom observations and audio-recordings; also, the researchers' field notes provided useful nonverbal contextual cues in identification of the "play frame" (shift to non-serious mode of conversation) and the interpretation of verbal humor. Prior to undertaking the project the researchers obtained ethical consent from the faculty, as well as participant lecturer and students. The audio-recorded data were transcribed and coded manually in line with the principles of coding qualitative data and category construction (Creswell, 2007; Geisler, 2004; Merriam, 2009).

Using the research objectives for guidance, several rounds of analysis were undertaken to code and categorize the data. Individually coded and categorized transcripts were exchanged among the researchers and the discrepancies were discussed until a reasonable concordance on appropriate categories was reached. In the first round, all verbal humor units (utterances) were identified. For this purpose, numerous clues regarding their 
inclusion were taken from previous research, including laughter and/or smiling responses from the audience, and paralinguistic, prosodic and discoursal indicators such as "unusual voices and pitch changes, very loud or quiet voices, and elongated sounds" (Bell, 2005). Also, when a speaker intended a meaning that "seemed to express non-conventional meaning and created a non-literal word" (Broner \& Tarone, 2001) it was regarded as an instance of humor. Excluded from the analysis were the few cases where there was doubt as to whether or not an utterance was intended to convey humor.

In the second round, the identified humorous utterances were assigned codes representing the strategies which drew on the textual knowledge resources to formulate and convey humor. It is worth mentioning that the distinction between "strategy" and "function" is not always clear-cut. This matter is explained by Hay (2000) who suggests that "strategies can be seen as more precise descriptions of functions" (p.717). In effect then, there is always some degree of overlap between strategy and function in verbal humor in discourse. However, what makes a strategy distinct from a function is the difference in the level of abstraction. That is, a strategy is identified as being less abstract than a function.

Finally, the third level of analysis involved identification of the different functions of humor use that can impact different aspects of classroom discourse such as teacher-student relationships, classroom culture, instructor and student perceptions and eventually the overall language teaching/learning processes. It should be noted that the data analyzed for the present paper come from a larger study that used qualitative and quantitative analysis to investigate different social, psychological, and instructional functions of humor and the effects of instructor humor as a discursive practice in an L2 context. However, here, the focus is directed to the "instructional functions" and the strategies used to fulfill such functions.

Although any humor used in L2 contexts might be of potential relevance to the use of the target language and/or its acquisition since humor is a part of any language, instructional functions here specifically refer to those aspects of instructor humor utilized to introduce, rehearse and illustrate the content/material of the target language and culture. It is therefore, specifically "word-based" types of humor that provide explicit or implicit opportunities for acquisition/learning of use and usage of the target language. Schmitz (2002) suggests that humor used in the language classroom discourse can be categorized into three types: universal or reality-based humor, culture-based humor, and linguistic or word-based humor. Universal humor has its origins in "the context and the general functioning of the world", culture-based humor involves the cultural knowledge that is embedded in the language, and word-based humor is created "based on specific features in the phonology, morphology or syntax of particular languages" (Schmitz, 2002, p.93). In light of Schmitz's grouping of humorous discourse, it can be said that instructional functions of humor encompass the instances of word-based and cultural humor that can enhance (socio)linguistic and sociocultural competence of L2 learners.

\section{Results and Discussion}

The following sections present the data and a discussion of how instances of verbal humor that occurred in classroom interactions may contribute to L2 learning. Based on an inductive analysis of the corpus, 124 spontaneous humor instances were identified and then classified under one of the three sub-categories "foregrounding form", "reinforcing meaning", and "highlighting cultural dissimilarities". These sub-categories represent the strategies used to fulfill instructional functions.

\subsection{Foregrounding Form}

One of the natural sources of humor in a language is the "incongruity" (see Berlyne, 1960) displayed in playing with and manipulating language forms. The present data suggest that verbal humor can be used as a strategy to bring form-based information to the foreground of attention in language teaching. That is, the use of humor instances such as puns, wordplays, tongue twisters, alliteration and so on, that entail playing with language form to construct humor in order to draw students' attention to formal aspects of the language. That 
The role of verbal humor in second language education

humor attracts student attention and that the increased attention can benefit student learning is well-recognized in previous research (see Davies \& Apter, 1980; Rassaei \& Karbor, 2013, Schmitz, 2002; Ziv, 1979). Consistent with this thinking, is the use of verbal humor as a device to bring linguistic information to the foreground of attention with a view to enhancing learning. As Bell (2005) summarizes, most studies on metalinguistic aspects of humor have shown that "explicit talk about language form and use can be a powerful learning device" (p.206).

Several examples from the data provide insights into the role of form-related humorous verbalizations in L2 learning. In the following example, the lecturer addresses a common syntactic error committed by L2 speakers in a non-native context such as Malaysia when using the English expression "pulling somebody's leg" (lines 1-2). In the excerpts below "T" stands for teacher/instructor, "Ss" for students and "S" for one student participating in humorous exchanges.

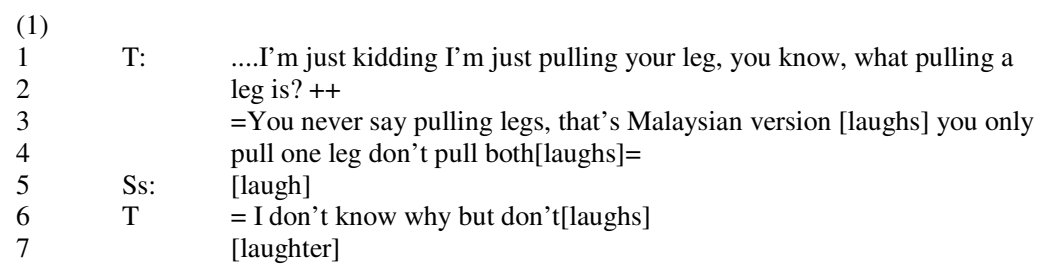

In this example, while putting it in a play frame, the lecturer underscores the correct usage (form) of the word "leg" in the English expression pulling sb's leg (lines 1-2).He also reminds his classroom audience that some L2 speakers use the plural form legs instead of its singular form leg; in reality this is a common mistake, so the instructor is emphasizing that students should be aware of such an error.

Similarly, in example 2 below, the instructor explicitly refers to the difference in pronunciation of the word "source" in British and American English.

(2)

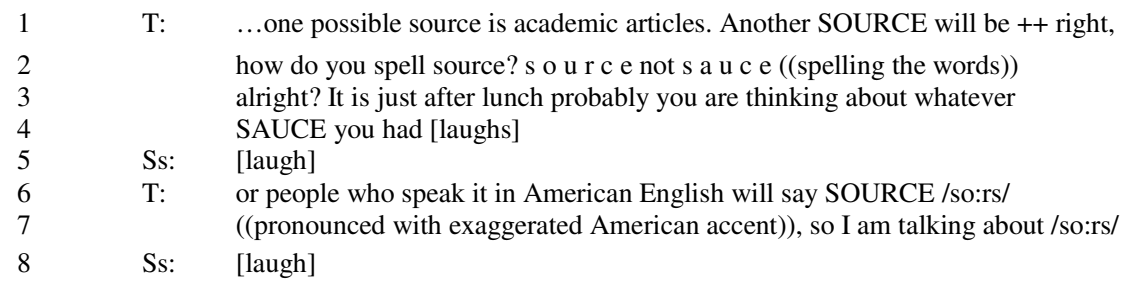

In lines 1-2, the instructor draws the students' attention to the phonological similarity between the words "source" and "sauce" (British pronunciation) while putting it in a play frame (lines 3-4). At the same time, he highlights the difference between the American and British pronunciation of the word "source" through explicit explanation of the spelling and pronunciation differences between the two words. The role of conscious attention to form in L2 learning already has been emphasized in previous research. Schmidt (2002) suggests that conscious attention to form or what is referred to as "noticing," is a necessary condition for L2 learning. In emphasizing the role of attention, he notes that "The concept of attention is necessary in order to understand virtually every aspect of second language acquisition" (Schmidt, 2002, p. 3). In the same vein, the role of language play in raising learners' awareness of L2 forms has been acknowledged by several humor researchers (e.g., Bell, 2005; Sullivan, 2000; Tarone, 2000). Consistent with previous research, the present data suggest that verbal humor that involves playing with and focusing on linguistic information can be a useful device to make L2 knowledge noticeable, and thereby facilitates access to L2 resources and L2 learning.

In the data there are further examples of humorous incidents that involve form-related language play. There is the use of pun and homonymy (words with the same spelling but different meaning) in utterances such as $I$ ' $m$ five foot. I have two feet but I'm five foot and Black humor is not black, as well as the use of homophony in the words sum and some, in ...sum of the parts does not equal the whole; sum of the parts, not some of the parts. Even though these examples per se may not convey "new" knowledge to the learners, they demonstrate that 
expressions contextualized in humorous utterances provide occasions for the acquisition of new L2 knowledge. In light of this, it would seem sound to claim that playing with language form to construct humor serves to help construct knowledge of the form. This is because, in order to understand and appreciate the employed humor, learners need to attend to the form and discover form-meaning relationships. In the following section we discuss the opportunities that verbal humor/language play offers for reinforcement of "meaning" in a second language.

\subsection{Foregrounding Form}

A second way in which humor is created in a language is through the incongruity inherent in idiomatic expressions and figurative speech. Most idioms in the target language are comprehended in regard to their specialized and figurative meaning rather than their literal meaning. In addition, most L2 idiomatic expressions often do not convey the same meaning as in L1. Hence, there is an incongruity between the usual and literal meanings of utterances within L2, as well as between L1 and L2, that often provides a potential source for the creation of humor. Given the existence of such incongruities humor can be used in regard to them as an instructional strategy to reinforce and expand meaning in a second language. Examples supporting this use of humor abound in the data. In Example (3) below, the instructor uses the idiomatic expression "in one piece" (line 2) meaning "not damaged or harmed" to construct humor.

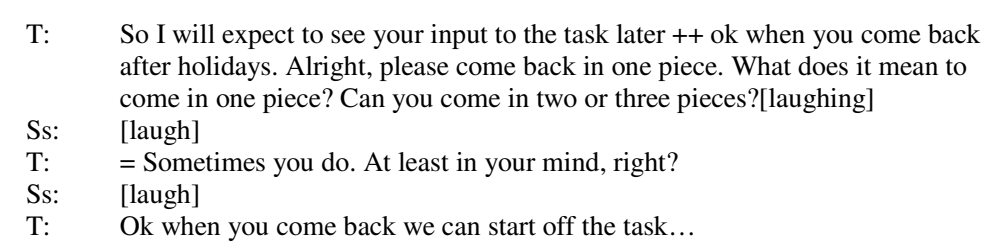

It can be seen from the instructor's probing question what does it mean to come in one piece? (lines 2-3) that, on the one hand he exploits this ironic expression in such a way as to draw students' attention to a linguistic point. The instructor's focus on the meaning of this expression can clearly help students remember the point. On the other hand, he uses funny alternatives of the expression (come in two or three pieces, line 3) to construct a sense of amusement and re-engage the students with the point being made. This can serve as a means of helping students to reformulate the concept of "come in one piece". Such humorous language play, as Bell (2005) notes, can bring L2 concepts into metalinguistic focus. In line with this view, one of the instructors involved in this research project who used humor in his teaching on a frequent basis, pointed out that "Intermingling language with humor is an effective way of teaching language".

Another way in which humor can be used to reinforce language learning is provided in Example (4) below. In an undergraduate sociolinguistics course the instructor was explaining the term "immersion" (a method of teaching a second language which uses the target language as a principal teaching tool, so that the learners are surrounded or "immersed" in the second language).

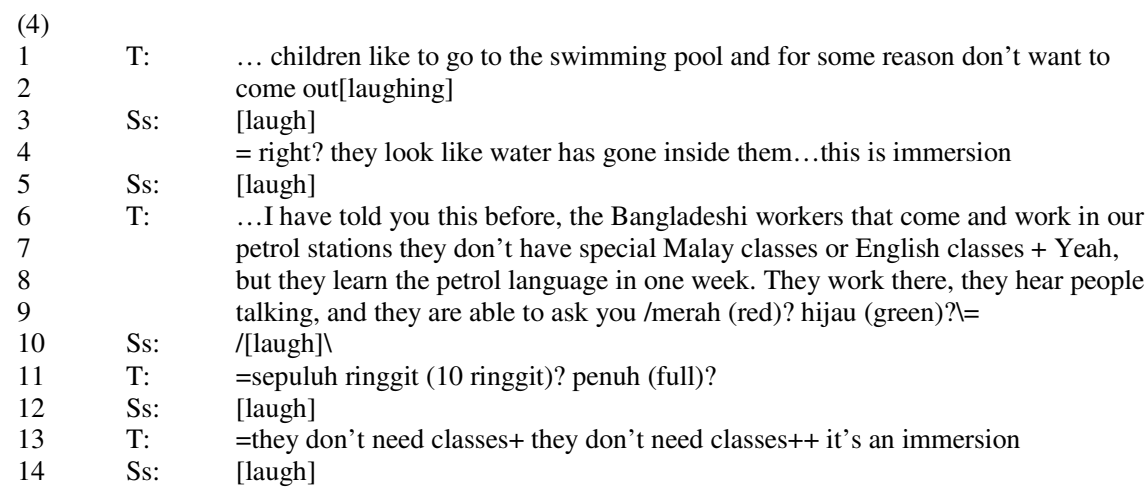

In this extract, the instructor makes a humorous analogy between "immersion" and children going swimming and notes that they sometimes get drowned in water (line 4). To further elaborate the point she also 
refers to the Bangladeshi workers who work in Malaysian gas stations and acquire the Malay language from the environment through the phenomenon called "immersion" (line 13). Through several code switching to the students' L1, which elicit rounds of laughter from the class (lines 9-12), she also gives examples of the language the workers acquire from the environment. Contextualization of L2 concepts in humorous situations, similar to that of the examples provided above, is believed to provide opportunities for L2 learners to notice new aspects of already established L2 meaning. As Bell (2005) notes, in such cases, where coherent amusing language is used to present new L2 resources/concepts, the opportunities for learning are enhanced and "when acquiring new meanings from context it is easier to learn a new word for a familiar concept than one for a new concept" (p.205).

Similarly, Example 5 below shows an instance of occasions when humor is used as a strategy to clarify a point and reinforce/expand the meaning of L2 concepts. The instructor asks students to define the concept of "metaphor" (line 1). Receiving no response from the class, she starts teasing them by using a metaphorical expression "your jaw dropped" (line 3) and through contextualization of the term in a play frame, she tries to implicitly get the meaning of "metaphor" across.

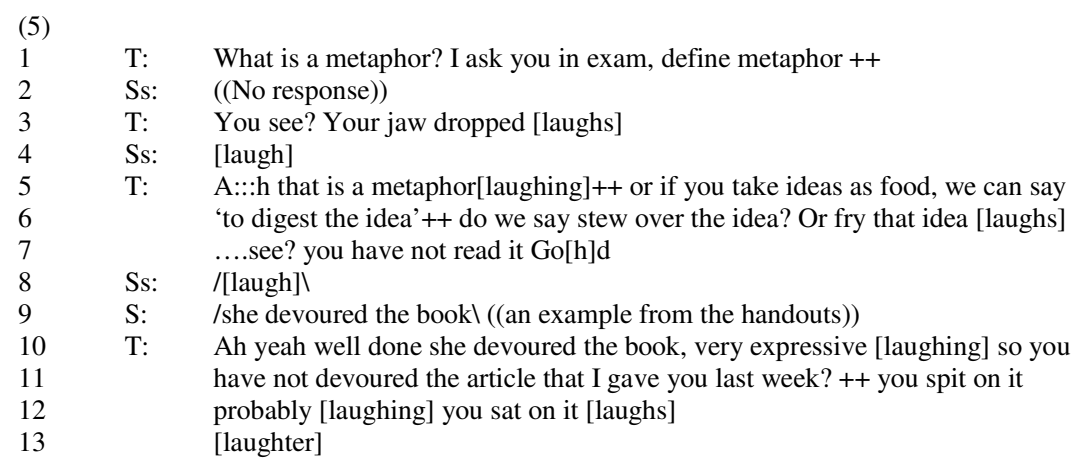

In lines 5-7, the instructor uses examples of metaphor such as digest the idea and stew over the idea to help students grasp the point. Following the instructor's examples, one student adds another example of metaphor, she devoured the book. Accepting her example (line 10) the instructor extends it with another metaphorical expression, so you have not devoured the article I gave you, (lines 10-11). She then continues by teasing the students with several humorous remarks, you spit on it and you sat on it (lines 11-12). Similar to example 4, in example 5 the instructor's contextualization of the concept of "metaphor" through the use of several authentic metaphorical phrases is clearly an effective strategy for expanding the meaning of the concept in the target language. Moreover, by situating the point in an amusing play frame, which attracts attention and exposes the learners to the different interpretations and meanings of the concept, the point is made more 'noticeable' and easier to remember. These examples demonstrate that humor can be used as a strategy to facilitate access to different interpretations/meanings of L2 resources. Specifically, it shows how humor that makes use of figurative language, which commonly bears double meaning, draws the learners' attention to various aspects of target language meaning including its serious and non-serious interpretations. In so doing the instructor can help the learners spot the differences between figurative and literal meaning.

\subsection{Highlighting Cultural Dissimilarities}

A third origin of humor in language relates to the 'incongruity' that is present where there are cultural dissimilarities. In addition to foregrounding form and reinforcing meaning (discussed earlier), the use of humor highlights cultural dissimilarities between L1 and L2, which can be used as a strategy to impart cultural knowledge. With respect to varying values, views, and attitudes of the interactants, understanding and appreciating L2 humor requires being informed about the cultural knowledge and the different culture-specific nuances in an L2 that are beyond the essential linguistic input. Hence, exposing learners to culture-related humor can shed light on the learners' sociocultural competence. Particularly in multilingual and multicultural instructional contexts, such as the setting of the present study in which the classroom hosts an amalgam of 
different languages such as Malay, Chinese, Indian, English, Turkish, Persian, Arabic, Indonesian, and African, as well as various dialects of these languages, there are many occasions for instilling humor in language education and expansion of cultural understanding.

Instances of culture-related humor in the data include instructors' sharing funny experiences, cracking cultural jokes, and telling personal anecdotes. Humor surfaces when instructors share with students how misunderstandings have happened, particularly in interactions with newcomers to the culture, both on and off campus. For example, one male instructor tells of his experience supervising a female student who used to come to supervision sessions along with her husband. The husband talked and asked questions more than the wife (the student). In another session, the instructor talks about a female student who brought her three year old child to supervision sessions. The instructor extends his humorous comments by saying: "I liked to play with the kid rather than give supervision to the mother". Having amused the class, the instructor acknowledges that, although the students' behaviors seemed funny for him at first, later he found that in the religion/culture, of these particular students it was not appropriate for a female adult to be alone with a man who was not 'mahram' to them. Mahram is an Arabic term meaning somebody (of the opposite sex) very close to you by blood or marriage.

These examples indicate that cultural knowledge can be evoked by humor. Therefore, if classroom humor is related to the target language culture, it must be a means of assisting learners' cultural understanding and eventually their sociocultural competence in L2. Several additional examples presented in the data support this understanding. For instance, in Extract 6 below the instructor is explaining to an undergraduate class how a host would treat a drop-by guest differently in Malaysian than in western cultures, and how a guest would/should behave in a different way according to the culture in which the event takes place.

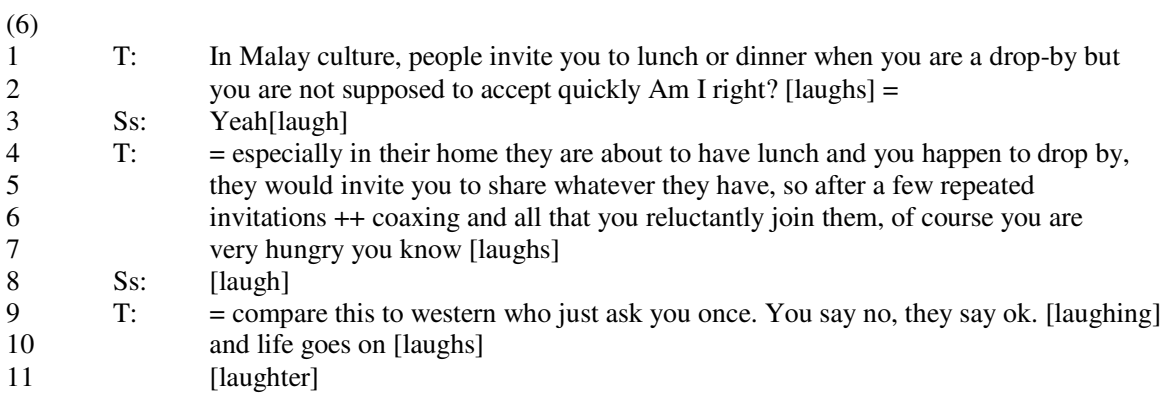

This humorous scenario, while it attracts the students' attention and elicits laughter from the floor (lines 8-11), helps to create an awareness of a subtle cultural dissimilarity between Malay and Western cultures. In this example the instructor described how in Malaysian culture, drop-by visitors expect to be treated when they happen to visit acquaintances around meal times. For the international students who do not share the cultural norms of Malaysians, it is obviously a new piece of information to learn that people are not supposed to accept the host's invitation quickly (line 2) when they are drop-by visitors, while in similar situations in western culture such 'coaxing' (line 6) and standing on ceremony to join the host for a meal is rarely expected.

\section{Conclusion}

The aim of this study was to examine the functions of instructors' humorous verbalizations and their instructional implications in academic ESL classrooms. As the data have demonstrated, the use of humorous language in an L2 learning environment provides a wide range of opportunities for acquiring/learning both relating to L2 form and meaning and understanding form-meaning connections, particularly the non-literal meaning of utterances as well as the cultural nuances inherent in most humorous exchanges. Although the present data do not provide evidence that there is learner development of linguistic and cultural knowledge, it is evident that language-based humor in an L2 classroom can make the linguistic and socio-cultural information embedded in the target language accessible to L2 learners, and this can quite possibly contribute to learners' 
The role of verbal humor in second language education

development of communicative competence (Hymes, 1972). There is also the implication that to understand and appreciate verbal humor in a second language, learners need to master specialized terminologies demanded by jokes, and gain the knowledge of humor communication in the target language. By the same token, the data suggest that L2 instructors too need to be linguistically and culturally competent in order to construct effective instructional humor if they want to enhance student language learning by this means. As Bell (2005) argues, "Successful construction of humor requires sophisticated linguistic and cultural knowledge in order to carefully select and place appropriate linguistic and extra-linguistic cues" (p.204).

Some attempts at humor were not appreciated by the students. The reasons might lie in their inability to understand the figurative aspect of humorous language and/or in the culture-specific nature of humor. Additionally, as our previous study indicated besides linguistic and cultural information, updated knowledge of the current events in the given context determines the way people understand and participate in humorous communication (see Ziyaeemehr et al., 2011).

Overall, the data suggest that humorous verbalizations in an L2 learning environment can function as devices for constructing and broadening L2 learners' knowledge of language form, meaning, and cultural understanding. In other words, the use of different forms of humor such as word plays, funny examples, puns, jokes, riddles, etc. highlights the linguistic and cultural information in the target language and provides opportunities for the learners to have access to new aspects of L2 (e.g. semantic, syntactic, phonological and pragmatic information). By the same token, as communication in a second language requires understanding of both serious and non-serious interpretations of utterances, humor functions as a mechanism that makes the input related to the non-serious side of the language accessible to the learners. In view of this, instructors' use of verbal humor can be perceived as an important instructional tool to rehearse both the use and usage of the language. It is also evident that humor elicits greater student involvement due to its attention-gaining nature which can eventually benefit acquisition/learning of a second language.

\section{Transcription conventions}

\begin{tabular}{|c|c|}
\hline++ & Pause of up to two seconds \\
\hline YEAH & Capitals indicate emphatic stress \\
\hline [h] & Laughing exhalation \\
\hline$(())$ & Detailed information \\
\hline [laughs]:: & Paralinguistic features in square brackets, colons indicate start/finish \\
\hline $\begin{array}{l}\ldots / \ldots \ldots 1 \ldots \\
\ldots / \ldots \ldots \ldots \perp \ldots\end{array}$ & Simultaneous speech \\
\hline$?$ & Rising or question intonation \\
\hline$=$ & Continued speech \\
\hline $\mathrm{L}$ & Lecturer \\
\hline $\mathrm{S}$ & Student \\
\hline Ss & Students \\
\hline
\end{tabular}

\section{References:}

Bell, N. (2005). Exploring L2 language play as an aid to SLL: A case study of humor in NS-NNS interaction. Applied Linguistics, 26(2), 192-218. http://dx.doi.org/10.1093/applin/amh043

Belz, J. A. (2002). Second language play as a representation of the multicompetent self in foreign language study. Journal of Language, Identity, and Education, 1, 13-39. http://dx.doi.org/10.1207/S15327701JLIE0101_3

Berlyne, D. E. (1960 ). Conflict, arousal, and curiosity. New York: McGraw-Hill. http://dx.doi.org/10.1037/11164-000

Bippus, A. M. (2000). Humor usage in comforting episodes: factors predicting outcomes. Western Journal of Communications, 64, 359-384.

Broner, M., \& Tarone, E. (2001). Is it fun? Language play in a fifth-grade Spanish immersion classroom. The Modern Language Journal, 85(3), 363-379. http://dx.doi.org/10.1111/0026-7902.00114 
Cook, G. (2000). Language play, language learning. Oxford: Oxford University Press.

Cook, V. (2002). Language teaching methodology and the L2 user perspective. In V. Cook (Ed.), Portraits of the L2 user (pp. 327-343). Clevedon: Multilingual Matters.

Creswell, J. W. (2007). Qualitative inquiry and research design: Choosing among five traditions (2nd ed). Thousand Oaks, CA: Sage.

Davies, A. P., \& Apter, M. J. (1980). Humor and its effect on learning in children. In P. E. McGhee \& A. J. Chapman (Eds.), Children's humor (pp. 237-254). New York: Wiley.

Davis, M. (2004). Stress management is key during nursing school. The Student Voice. Retrieved April 15, 2011 from http://www.onsopcontent.ons.org/Publications/StudentVoice/Nov04/article5.

Deneire, M. (1995). Humor and foreign language teaching. Humor: International Journal of Humor Research, 8(3), 285-298. http://dx.doi.org/10.1515/humr.1995.8.3.285

Downs, V. C., Javidi, M., \& Nussbaum, J. F. (1988). An analysis of teachers' verbal communication within the college classroom: Use of humor, self-disclosure, and narratives. Communication Education, 37(2), 127-141. http://dx.doi.org/10.1080/03634528809378710

Fairclough, N. (1995). Critical discourse analysis. London, England: Longman.

Fairclough, N. (2001). Language and Power (2nd ed.). London, UK: Longman.

Fraley, B., \& Aron, A. (2004). The effect of a shared humorous experience on closeness in initial encounters. Personal Relationships, 11(1), 61-78. http://dx.doi.org/10.1111/j.1475-6811.2004.00071.x

Garner, R. L. (2006). Humor In Pedagogy: How Ha-Ha Can Lead To Aha! College Teaching (1), 54.

Geisler, C. (2004). Analyzing streams of language: Twelve steps to the systematic coding of text, talk, and other verbal data. New York: Longman.

Gorham, J., \& Christophel, D. M. (1990). The relationship of teachers' use of humor in the classroom to immediacy and student learning. Communication Education, 39(1), 46-62.

Hay, J. (2000). Functions of humor in the conversations of women and men. Journal of Pragmatics, 32 (6), 709-742. http://dx.doi.org/10.1016/S0378-2166(99)00069-7

Holmes, J. (2000). Politeness, power and provocation: how humor functions in the workplace. Discourse Studies, 2(2), 159-185.

Holmes, J., \& Marra, M. (2002). Having a laugh at work: how humour contributes to workplace culture. Journal of Pragmatics, 34, 1683-1710. http://dx.doi.org/10.1016/S0378-2166(02)00032-2

Hymes, D. (1972). On communicative competence. In J. B. Pride \& J. Holmes (Eds.), Sociolinguistics: Selected Readings (pp. 269-293): Penguin, Harmondsworth, UK.

Lantolf, J. (1997). The function of language play in the acquisition of L2 Spanish. In W. R. Glass and A. T. Perez-Leroux (Eds): Contemporary Perspectives on the Acquisition of Spanish. Somerville, MA: Cascadilla Press, pp. 3-24.

Martin, R. A. (2007). The psychology of humor: An integrative approach. Burlington, MA: Elsevier Inc.

Merriam, S. B. (2009). Qualitative research: A guide to design and implementation. San Francisco, CA: Jossey-Bass.

McCroskey, J. C., Richmond, V. P., \& Bennett, V. E. (2006). The relationships of student end-of-class motivation with teacher communication behaviors and instructional outcomes. Communication Education, 55(4), 403-414. http://dx.doi.org/10.1080/03634520600702562

Medgyes, P. (2002). Laughing Matters: Humor in the language classroom. Cambridge: Cambridge University Press.

Morreall, J. (1983). Taking Laughter Seriously. Albany State University of New York Press.

Neuliep, J. W. (1991). An examination of the content of high school teacher's humor in the classroom and the development of an inductively derived taxonomy of classroom humor. Communication Education, 40, 343-355. http://dx.doi.org/10.1080/03634529109378859

Norrick, N. R. (1993). Conversational Joking: Humor in Everyday Talk. Bloomington: Indiana University Press.

Priest, R. F., \& Thein, M. T. (2003). Humor appreciation in marriage: spousal similarity, assortative mating, and disaffection. Humor - International Journal of Humor Research, 16, 63-78. http://dx.doi.org/10.1515/humr.2003.005 
The role of verbal humor in second language education

Rassaei, E., \& Karbor, T. ( 2013). The effects of three types of attention drawing techniques on the acquisition of English collocations. International Journal of Research Studies in Language Learning, 2(2), 15-28. http://dx.doi.org/10.5861/ijrsll.2012.117

Raskin, V. (1985). Semantic Mechanisms of Humor. Dordrecht: D. Reidel.

Raskin, V., \& Attardo, S. (1994). Non-literalness and non-bona-fide in language: An approach to formal and computational treatments of humor. Pragmatics \& Cognition, 2(1), 31-69. http://dx.doi.org/10.1075/pc.2.1.02ras

Schmidt, S. R. (2002). The effect of humor: Differential processing and privileged retrieval. Memory, 10(2), 127-138. http://dx.doi.org/10.1080/09658210143000263

Schmitz, J. R. (2002). Humor as a pedagogical tool in foreign language and translation courses. Humor: International Journal of Humor Research, 15(1), 89-113. http://dx.doi.org/10.1515/humr.2002.007

Sullivan, P. (2000). Playfulness as mediation in communicative language teaching in a Vietnamese classroom. In J. P. Lantolf (Ed.), Sociocultural Theory and Second Language Learning. Oxford University Press.

Wanzer, M. (2002). Use of humor in the classroom: The good, the bad, and the not-so funny things that teachers say and do. In J. L. C. J. C. McCroskey (Ed.), Communication for Teachers (pp. 116-126). Boston: Allyn \& Bacon.

Wanzer, M. B., Frymier, A. B., \& Irwin, B. (2009). An explanation of the relationship between teacher humor and student learning: Instructional humor processing theory. Paper presented at the annual meeting of the Eastern Communication Association.

Wanzer, M., B., Frymier, A., B., Wojtaszczyk, A., M., \& Smith, T. (2006). Appropriate and inappropriate uses of humor by teachers. Communication Education, 55, 178-196. http://dx.doi.org/10.1080/03634520600566132

Wanzer, M., Booth-Butterfield, M., \& Booth-Butterfield, S. (2005). "If we didn't use humor we'd cry": Use of humor as coping in healthcare. Journal of Health Communication, 10, 105-125. http://dx.doi.org/10.1080/10810730590915092

Weir, R. H. (1962). Language in the crib. The Hague Mouton.

Wrench, J., \& Booth-Butterfield, M. (2003). Increasing patient satisfaction and compliance: An examination of physician humor orientation, compliance gaining strategies, and perceived credibility. Communication Quarterly, 51, 482-503. http://dx.doi.org/10.1080/01463370309370169

Yoon, Bogum \& Kim, Hoe Kyeung. (Eds). (2012). Teacher's Roles in Second Language Learning. Classroom Applications of Sociocultural Theory. Charlotte, NC: Information Age Publishing, Inc.

Ziv, A. (1979). L'humor en education: Approche psychologique. Paris: Editions Social Francaises.

Ziv, A. (1988). Teaching and learning with humor: Experiment and replication. Journal of Experimental Education, 57, 5-15.

Ziyaeemehr, A., Kumar, V., \& Faiz, S. A. (2011). Use and Non-use of Humor in Academic ESL Classrooms. English Language Teaching, (4)3, 111-119. 
Ziyaeemehr, A. \& Kumar, V. 